\title{
Geographic Differences in Endovascular Treatment and Retreatment of Cerebral Aneurysms
}

\author{
(D)A.S. Turk, (D)S.C. Johnston, (D)S. Hetts, (D). Mocco, (D). English, (D). Murayama, (D) C.J. Prestigiacomo, (DD. Lopes, (D).P. Gobin, \\ (iD. K. Carroll, and DC. McDougall
}

\begin{abstract}
BACKGROUND AND PURPOSE: Comparing outcomes between endovascular aneurysm coiling trials can be difficult because of heterogeneity in patients and end points. We sought to understand the impact of geography on aneurysm retreatment in patients enrolled in the Matrix and Platinum Science Trial.
\end{abstract}

MATERIALS AND METHODS: Post hoc analysis was performed on data from the Matrix and Platinum Science trial. Patients were stratified as either North American or international. Baseline patient demographics, comorbidities, aneurysm characteristics, procedural complications, and clinical and angiographic outcomes were compared.

RESULTS: We evaluated 407 patients from 28 North American sites and 219 patients from 15 international sites. Patient demographics differed significantly between North American and international sites. Aneurysms were well occluded postprocedure more often at international than North American sites $(P<.001)$. Stents were used significantly more often at North American sites (32.7\% [133 of 407]) compared with international sites (10.0\% [22 of 219]; $P<.001)$. At 455 days, there was no difference in the proportion of patients alive and free of disability $(P=.56)$ or with residual aneurysm filling $(P=.10)$. Ruptured aneurysms were significantly more likely to have been retreated at North American sites within the first year $(P<.001)$ and at 2 years $(P<.001)$. Among all patients for whom the treating physician believed there to be Raymond 3 aneurysm filling at follow-up, absolute rates of retreatment at international and North American sites were similar by 2-year follow-up.

CONCLUSIONS: Data from the Matrix and Platinum Science Trial demonstrate that aneurysm retreatment occurs with different frequency and at different times in different regions of the world. This trend has critical value when interpreting trials reporting short-term outcomes, especially when judgment-based metrics such as retreatment are primary end points that may or may not take place within the defined study follow-up period. Though these variations can be controlled for and balanced within a given randomized trial, such differences in practice patterns must be accounted for in any attempt to compare outcomes between different trials. Despite these differences, endovascular-treated intracranial aneurysms around the world have similar clinical outcomes.

$\mathbf{T}$ he International Subarachnoid Aneurysm Trial ${ }^{1,2}$ was the landmark prospective randomized trial demonstrating the safety and effectiveness of endovascular treatment of ruptured aneurysms compared with surgical clipping. More recently, results from the Barrow Ruptured Aneurysm Trial ${ }^{3}$ further support

\footnotetext{
Received February 2, 2016; accepted after revision May 5.

From the Departments of Radiology (A.S.T.) and Neurosurgery (A.S.T.), Medical University of South Carolina, Charleston, South Carolina; Clinical and Translational Science Institute (S.C.J.), University of California, San Francisco, San Francisco, California; Dell Medical School at The University of Texas at Austin (S.C.J.), Austin, Texas; Department of Radiology and Biomedical Imaging (S.H.), University of California, San Francisco School of Medicine, San Francisco, California; Department of Neurosurgery (I.M.), Icahn School of Medicine at Mount Sinai, New York, New York; California Pacific Medical Center (J.E.), San Francisco, California; Department of Neurosurgery (Y.M.), Jikei University Hospital, Tokyo, Japan; Department of Neurological Surgery (C.J.P.), University of Medicine and Dentistry of New Jersey, Newark, New Jersey; Department of Neurosurgery (D.L.), Rush University Medical Center, Chicago, Illinois; Department of Neurosurgery (Y.P.G.), Weill Cornell Medical College,
}

coiling as a treatment technique associated with good patient outcomes comparable with clipping in the setting of SAH. Moreover, the results of several recently published multinational randomized controlled trials ${ }^{4-6}$ demonstrated ruptured and unruptured aneurysms can be safely and effectively treated by using various coil types. Many comparisons generalizing results of these various trials have been made. However, comparing outcomes between trials can be difficult and misleading because of different trial

New York, New York; Stryker Corporation (K.C.), Fremont, California; and Department of Neurosurgery (C.M.), Barrow Neurological Institute, St. Joseph's Hospital and Medical Center, Phoenix, Arizona.

Please address correspondence to Aquilla S. Turk, III, DO, Departments of Radiology and Neurosurgery, Medical University of South Carolina, Charleston, SC 29425; e-mail: turk@musc.edu

http://dx.doi.org/10.3174/ajnr.A4857 
Table 1: Patient demographics

\begin{tabular}{|c|c|c|c|}
\hline \multirow[b]{2}{*}{ Variable } & \multicolumn{2}{|c|}{ Location, (n [\%]) } & \multirow[b]{2}{*}{$P$ Value } \\
\hline & North America & International & \\
\hline Total patients & 407 & 219 & \\
\hline No. of sites & 28 & 15 & \\
\hline Female sex & $309(75.9 \%)$ & $131(59.8 \%)$ & $<.001$ \\
\hline Age $>55 \mathrm{yr}$ & $218(53.6 \%)$ & $88(40.2 \%)$ & $<.001$ \\
\hline White & $350(86.0 \%)$ & $158(72.1 \%)$ & $<.001$ \\
\hline Current/previous smoker & $261(64.1 \%)$ & $130(59.4 \%)$ & .24 \\
\hline$>1$ cardiovascular risk factor & $124(30.5 \%)$ & $33(15.1 \%)$ & $<.001$ \\
\hline Hypertension & $217(53.3 \%)$ & $83(37.9 \%)$ & $<.001$ \\
\hline Hyperlipidemia/hypercholesterolemia & $122(30.0 \%)$ & $34(15.5 \%)$ & $<.001$ \\
\hline Diabetes & $43(10.6 \%)$ & $11(5.0 \%)$ & .02 \\
\hline Coronary disease & $63(15.5 \%)$ & $10(4.6 \%)$ & $<.001$ \\
\hline Prior cerebrovascular accident & $54(13.3 \%)$ & $15(6.8 \%)$ & .02 \\
\hline $\begin{array}{l}\text { Hunt and Hess grade } 3 \text { or } 4 \text { in ruptured } \\
\text { patients }\end{array}$ & $38 / 115(33.0 \%)$ & $24 / 113(21.2 \%)$ & .045 \\
\hline
\end{tabular}

designs and patient populations. ${ }^{7}$ Analyses of subgroups from different trials cannot overcome these problems.

The very low bleeding or rebleeding rates of treated aneurysms has led most trial investigators to use angiographic outcomes to compare device performance. However, there are no agreed-upon standards for acceptable angiographic outcomes. Recently, the value of target aneurysm recurrence was explored as a new clinically relevant composite end point in a large-scale multicenter randomized trial comparing outcomes of patients with intracranial saccular aneurysms treated with 2 different embolic coil types. ${ }^{4,8,9}$ In this study, target aneurysm recurrence was defined as clinically relevant aneurysm recurrence resulting in target aneurysm re-intervention, rupture/rerupture, and/or death from an unknown cause. The advantage of this end point is that it is definitive that the event has happened and that these events are of clear relevance to the patient. The disadvantage of these end points is the variability of the decision to retreat because physician judgment often varies with the training, economic incentives, and regulatory structure of the local health system.

Both angiographic assessments and the decision to retreat aneurysms are subjective, leaving tremendous opportunity for individual or regional factors to influence trial results. We sought to understand the impact of geography on aneurysm retreatment in patients randomized in the Matrix and Platinum Science Trial.

\section{MATERIALS AND METHODS}

The Matrix and Platinum Science Trial was a randomized controlled trial of 626 intent-to-treat patients. The methodology and primary outcomes of this trial have been previously published. ${ }^{4}$ Anticipating variability in retreatment rates across enrolling sites, the trial stratified randomization by both aneurysm rupture status and enrolling site. For this analysis, the Matrix and Platinum Science Trial data base was interrogated and all aneurysms divided into groups based on geographic location of the medical center where they were treated. All baseline patient demographics, including cardiovascular risk factors, were documented. Aneurysm location, rupture status, and characteristics were also evaluated. Angiographic and clinical outcomes were compared. An independent core radiology laboratory performed all angiographic analyses.

All patients in the Matrix and Platinum Science Trial were used for this analysis. For data dependent upon core laboratory angiographic analysis, patients with unreadable images were excluded. Patients were categorized into 2 groups: North American and international sites (including sites in Europe, Australia, and China). Few patients were enrolled in Asia and Australia; therefore, they were combined with Europe to create the complete international cohort. Patients were further explored based on their baseline rupture status, comorbidities, and angiographic core laboratory evaluations. Retreatment rates within each subgroup were calculated and compared.

We used logistic regression modeling to answer our research questions: 1) "What are the predictive characteristics of retreatment in ruptured and unruptured aneurysms?" and 2) "Are there differences in retreatment rates between geographies?" All baseline aneurysm characteristics and immediate postprocedure angiography readings by the core laboratory were first tested in univariate models to determine the association with the retreatment outcome. All potential covariates with a $P$ value $\leq .10$ in a univariate model were included in the covariate pool drawn upon during the stepwise multivariate model selection process. In the final model, only those covariates with a $P$ value $<.05$ were retained. Finally, to control for potential site effect, we used a generalized linear mixed-effect model within the 2 subsets of baseline ruptured or unruptured cohorts. In this model, we specified "site" as the random effect so that retreatment rates were not assumed to be equal among sites and, therefore, we could estimate common odds ratios across sites. Geography and stent usage (for unruptured aneurysms) were forced as fixed effects.

Kaplan-Meier survival curves were constructed to evaluate the difference in days to first retreatment between North American and international patient subgroups. Separate curves were constructed for baseline ruptured and baseline unruptured patients. The log-rank test was used for the $P$ value calculations of the difference between the 2 curves from 2 regions.

\section{RESULTS}

Between March 2007 and October 2009, 626 patients were randomized into the Matrix and Platinum Science Trial at 43 sites in 11 countries. Among 407 North American patients enrolled at 28 sites, 115 had ruptured aneurysms and 292 had unruptured aneurysms. The 15 international sites treated 219 patients, of whom 113 had ruptured aneurysms and 106 had unruptured aneurysms. (Table 1). Approximately $95 \%$ of patients in both the North American and international subgroups had follow-up data available after 1 year ( $>275$ days); follow-up data were available after 2 years ( $>640$ days) for $81.0 \%$ and $84.5 \%$ of North American and international patients, respectively.

\section{Baseline Demographics}

Patient demographics differed between North American and international groups, with the most significant differences being the 
proportions of female patients with ruptured aneurysms, white patients, and patients with more than 1 cardiovascular risk factor (Table 1 and Table 2).

\section{Angiographic and Clinical Outcomes}

Core laboratory occlusion assessment was performed by using the modified 3-point Raymond scale. ${ }^{10}$ Immediately postprocedure, a higher proportion of patients treated at North American sites

Table 2: Aneurysm characteristics

\begin{tabular}{lccc}
\hline & \multicolumn{2}{c}{ Location, $(\boldsymbol{n}[\%])$} & \\
\cline { 2 - 3 } \multicolumn{1}{c}{ Variable } & $\begin{array}{c}\text { North } \\
\text { America }\end{array}$ & International & $\begin{array}{c}\boldsymbol{P} \\
\text { Value }\end{array}$ \\
\hline Total patients & 407 & 219 & \\
Aneurysm size $>10 \mathrm{~mm}$ & $85(20.9 \%)$ & $45(20.5 \%)$ & .92 \\
Posterior circulation aneurysm & $65(16.0 \%)$ & $18(8.2 \%)$ & $<.001$ \\
Aneurysm neck width $\geq 4 \mathrm{~mm}$ & $159(39.1 \%)$ & $67(30.6 \%)$ & .04 \\
Ruptured aneurysm & $115(28.3 \%)$ & $113(51.6 \%)$ & $<.001$ \\
Dome-to-neck ratio $<1.5$ & $118(29.0 \%)$ & $53(24.2 \%)$ & .20 \\
\hline
\end{tabular}
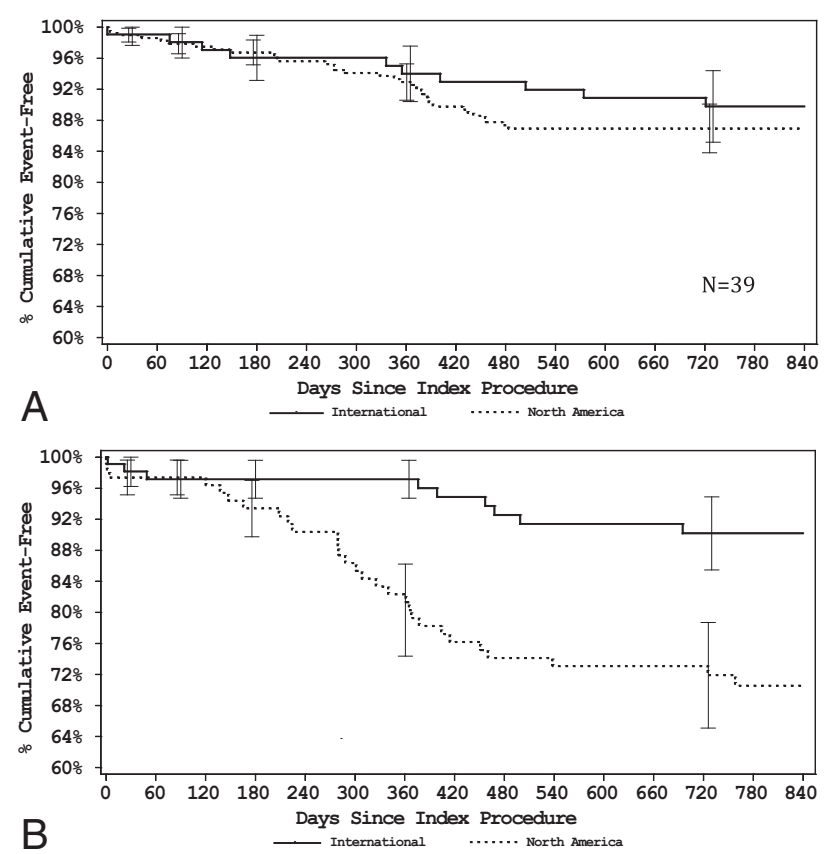

FIGURE. A, Unruptured aneurysms-freedom from retreatment. B, Ruptured aneurysms - freedom from retreatment.

Table 3: Multivariate analysis: predictors of retreatment for 398 unruptured aneurysms

\begin{tabular}{|c|c|c|c|c|}
\hline \multirow[b]{3}{*}{ Parameter } & \multicolumn{4}{|c|}{ Follow-Up } \\
\hline & \multicolumn{2}{|c|}{455 Days } & \multicolumn{2}{|c|}{820 Days } \\
\hline & OR $(95 \% \mathrm{CI})$ & $P$ Value & OR $(95 \% \mathrm{Cl})$ & $P$ Value \\
\hline Dome size ( $\geq 10 \mathrm{~mm}$ vs $<10 \mathrm{~mm})$ & 4.12 (1.19-14.2) & .0253 & $5.28(1.58-17.7)$ & .0071 \\
\hline Neuroform ${ }^{\mathrm{a}}$ used at index 1 vs 0 & $0.54(0.20-1.44)$ & .2142 & $0.49(0.19-1.23)$ & .1269 \\
\hline Neck size ( $\geq 4 \mathrm{~mm}$ vs $<4 \mathrm{~mm}$ ) & $1.39(0.47-4.13)$ & .5470 & $1.85(0.71-4.83)$ & .2068 \\
\hline North America 1 vs 0 & $2.22(0.69-7.14)$ & .1788 & $1.53(0.57-4.08)$ & .3973 \\
\hline $\begin{array}{l}\text { Core laboratory postprocedure } \\
\text { Raymond scale } 2 \text { vs } 1\end{array}$ & $1.13(0.24-5.39)$ & .8759 & $0.79(0.21-2.97)$ & .7313 \\
\hline $\begin{array}{l}\text { Core laboratory postprocedure } \\
\text { Raymond scale } 3 \text { vs } 1\end{array}$ & $3.62(1.06-12.4)$ & .0405 & $2.31(0.84-6.38)$ & .1056 \\
\hline $\begin{array}{l}\text { Aneurysm size ( }<10 \mathrm{~mm} \\
\text { vs } \geq 10 \mathrm{~mm} \text { ) }\end{array}$ & $0.40(0.11-1.42)$ & .1576 & $0.62(0.19-1.99)$ & .4212 \\
\hline
\end{tabular}

Note:-OR indicates odds ratio.

${ }^{\text {a }}$ Stryker Neurovascular, Kalamazoo, Michigan. had a Raymond score of 3 (residual aneurysm) compared with patients at international sites $(43.5 \%$ [ 140 of 322] versus $26.5 \%$ [44 of 166]; $P<.001$ ). This higher proportion of postprocedure residual aneurysms among North American patients was observed in both ruptured (29.8\% [28 of 94] versus $16.7 \%$ [ 13 of 78 ]) and unruptured (49.1\% [ 112 of 228 ] versus $35.2 \%$ [ 31 of 88 ]) subgroups. However, the proportion of patients with a packing attenuation $>25 \%$ was similar in North American (42.5\% [173 of 407]) and international (38.4\% [ 84 of 219]) groups. Stents were used more frequently in unruptured aneurysms treated in North American than international sites ( $44 \%$ versus $19 \%$, respectively; $P<.001$ ).

At 30 days, patients with ruptured aneurysms were more likely to have been discharged from North American sites than patients treated at international sites (85.2\% [98 of 115] versus $66.4 \%$ [75 of 113]; $P<.001)$.

At 455 days, there was no difference in the proportion of patients alive and free of disability among those with ruptured aneurysms (North American: 90.4\% [94 of 104] versus international: $94.0 \%$ [94 of 100]) and unruptured aneurysms (North American: 95.4\% [250 of 262] versus international: 97.0\% [97 of $100])$ and no significant difference in the proportion of patients with core laboratory adjudicated residual aneurysms (36.4\% versus $28.7 \% ; P=.10$ ). Ruptured aneurysms were more likely to have been retreated at North American sites compared with international sites $(21.7 \%$ versus $4.4 \% ; P<.001)$, whereas there were no significant regional differences in retreatment rates among patients with unruptured aneurysms. Kaplan-Meier curves demonstrate no difference in freedom from retreatment in patients in the unruptured group and a sustained difference in patients in the ruptured group (Figure).

Multivariate analysis of ruptured aneurysms at 455 days demonstrated that geography (adjusted common odds ratio 6.2; 95\% CI, 2.0-18.8; $P<.001$ ), neck size $\geq 4 \mathrm{~mm}$ (adjusted common odds ratio 4.3 ; 95\% CI, 1.6-11.5; $P=.004$ ), and residual aneurysm on postprocedure angiogram (adjusted common odds ratio 7.2; 95\% CI, 2.6-19.7; $P<.001)$ were the most significant predictors of retreatment (Table 3 ). For unruptured aneurysms at 455 days, dome size $\geq 10 \mathrm{~mm}$ (adjusted common odds ratio 4.1; 95\% CI, 1.2-14.2; $P=.025$ ) and residual aneurysm on postprocedure angiogram (adjusted common odds ratio 3.6; 95\% CI, 1.1-12.4; $P=$ .040 ) were significant predictors of retreatment. Geography was not an independent predictor of retreatment in unruptured aneurysms.

Multivariate analysis of ruptured aneurysms at 820 days demonstrated that predictors of retreatment did not change from 455 days (Table 4). In the unruptured cohort, the only significant predictor of retreatment at 820 days was dome size $\geq 10 \mathrm{~mm}$ (adjusted common odds ratio $5.3 ; 95 \% \mathrm{CI}, 1.6-17.7 ; P=$ .007). Postprocedure angiographic results were no longer significant at 820 days.

\section{DISCUSSION}

One of the most striking findings in this study is the significantly higher retreatment rate of aneurysms in North Amer- 
Table 4: Multivariate analysis: predictors of retreatment for 228 ruptured aneurysms

\begin{tabular}{|c|c|c|c|c|}
\hline \multirow[b]{3}{*}{ Parameter } & \multicolumn{4}{|c|}{ Follow-Up } \\
\hline & \multicolumn{2}{|c|}{455 Days } & \multicolumn{2}{|c|}{820 Days } \\
\hline & OR $(95 \% \mathrm{Cl})$ & $P$ Value & OR $(95 \% \mathrm{CI})$ & $P$ Value \\
\hline Dome size ( $\geq 10 \mathrm{~mm}$ vs $<10 \mathrm{~mm}$ ) & $7.45(0.82-67.4)$ & .0737 & $2.63(0.30-23.2)$ & .3831 \\
\hline Neuroform ${ }^{\mathrm{a}}$ used at index 1 vs 0 & $7.99(1.40-45.5)$ & .0195 & $3.03(0.42-22.1)$ & .2717 \\
\hline Neck size ( $\geq 4 \mathrm{~mm}$ vs $<4 \mathrm{~mm}$ ) & $4.30(1.60-11.5)$ & .0041 & $3.11(1.14-8.52)$ & .0273 \\
\hline North America 1 vs 0 & $6.19(2.04-18.8)$ & .0014 & $3.42(1.28-9.15)$ & .0145 \\
\hline $\begin{array}{l}\text { Core laboratory postprocedure } \\
\text { Raymond scale } 2 \text { vs } 1\end{array}$ & $1.27(0.39-4.13)$ & .6930 & $1.02(0.30-3.50)$ & .9694 \\
\hline $\begin{array}{l}\text { Core laboratory postprocedure } \\
\text { Raymond scale } 3 \text { vs } 1\end{array}$ & $7.17(2.61-19.7)$ & .0002 & $6.24(2.29-17.0)$ & .0004 \\
\hline $\begin{array}{l}\text { Aneurysm size ( }<10 \mathrm{~mm} \\
\text { vs } \geq 10 \mathrm{~mm} \text { ) }\end{array}$ & $7.96(1.45-43.7)$ & .0174 & $1.08(0.29-4.06)$ & .9050 \\
\hline
\end{tabular}

Note:-OR indicates odds ratio.

a Stryker Neurovascular, Kalamazoo, Michigan.

ica, especially among ruptured aneurysms and in the first 455 days postprocedure. Though the difference in retreatment rates between North America and international sites was persistent out to 820 days (Figure), there appears to be eventual consistency in global retreatment rates among patients judged to have residual aneurysms at follow-up. At 820 days, 55.7\% of North American residual aneurysms had been retreated compared with $47.6 \%$ in international sites. Earlier in follow-up, at 455 days, $49.2 \%$ of North American residual aneurysms had already been retreated compared with just $19.0 \%$ of international residual aneurysms.

The geographic differences in frequency of retreatment were only significant in the ruptured aneurysm cohort. This could indicate a North American preference to treat the rupture minimally, with a willingness to do a follow-up retreatment if necessary. It also may be tied to an increased use of stents in patients with unruptured aneurysms in North America, though multivariate analysis did not show the impact of stents on retreatment rates to be significant at 455 or 820 days (Table 3 ).

Differences between geographies were present, beginning with patient baseline characteristics and extending through aneurysm treatment and subsequent follow-up. North American operators treated significantly more patients who were older in age with multiple cardiovascular risk factors and more likely to have a higher Hunt and Hess grade. When North American operators identified residual aneurysm filling at follow-up, they were more likely to immediately retreat these remnants than operators in other regions of the world.

A significantly higher proportion of aneurysms treated at North American sites had residual filling immediately postprocedure than aneurysms treated at international sites (43.5\% versus $26.5 \%$, respectively). These initial occlusion rates indicate a more aggressive treatment approach at international sites. However, similar packing densities across regions imply that physicians are implanting similar volumes of coils. This discrepancy could be attributed to complex aneurysm morphologies and the imperfect nature of packing attenuation calculations that assume an elliptical aneurysm shape.

Stent-assisted coiling was used significantly more frequently in North America and was associated with better angiographic outcomes at 455 days than aneurysms treated by coiling alone. Though there were more ischemic events associated with stented aneurysms, multivariate analysis demonstrated that this was because of the width of the aneurysm neck and a history of stroke. ${ }^{11}$

Despite these differences, there was no significant difference in mRS between North American and international cohorts at 455 days.

Though these data of 626 patients are strengthened through the prospective randomized trial design, retrospective identification of subgroups for analysis remains a limitation. The utilization of an angiographic core laboratory also further strengthens the data, though 21.1\% of North American patients and $25.1 \%$ of international patients had no core laboratory reading at 455 days because of image quality issues or other protocol violations. Although we have used statistical models to create common odds ratios for estimation of predictive characteristics of retreatment, the management of intracranial aneurysms may potentially be different from site to site and country to country. Therefore, inferences of predictive characteristics of various treatment modalities remain a limitation of our analysis and require future powered randomized controlled studies.

\section{CONCLUSIONS}

Data from the Matrix and Platinum Science Trial demonstrate that aneurysm retreatment occurs with different frequency and at different times in different regions of the world. This trend has critical value when interpreting trials reporting short-term outcomes, especially when judgment-based metrics such as retreatment are primary end points that may or may not take place within the defined study follow-up period. Though these variations can be controlled for and balanced within a given randomized trial, such differences in practice patterns must be accounted for in any attempt to compare outcomes among different trials. Despite these differences, endovascular-treated intracranial aneurysms around the world have similar clinical outcomes.

Disclosures: Aquilla S. Turk—RELATED: Grant: Stryker Medical, ${ }^{*}$ Comments: fellowship grant; Consulting Fee or Honorarium: Stryker Medical, Comments: speaking engagements (no payment); Support for Travel to Meetings for the Study or Other Purposes: Stryker Medical, Comments: airfare and hotel booking for conferences and speaking engagements; UNRELATED: Consultancy: Penumbra, ${ }^{*}$ Microvention,* Medina Medical*; Grants/Grants Pending: Microvention, ${ }^{*}$ Penumbra*; Payment for Lectures (including service on speakers bureaus): Penumbra, ${ }^{*}$ Covidien, ${ }^{*}$ Microvention, ${ }^{*}$ Medina Medical, ${ }^{*}$ Siemens. ${ }^{*}$ Steven Hetts—RELATED: Grant: Stryker Neurovascular, ${ }^{\star}$ Comments: University of California, San Francisco was the core angiographic imaging laboratory for the Matrix and Platinum Science Trial; UNRELATED: Consultancy: Stryker Neurovascular, Comments: occasional educational presentations to company employees on diagnosis and treatment of stroke; Grants/Grants Pending: Stryker Neurovascular, ${ }^{*}$ Microvention,, Terumo,* Siemens,* Comments: University of California, San Francisco is the core imaging laboratory for the Adjuvant Tamoxifen: Longer Against Shorter (ATLAS), Surpass Flow Diverter for Intracranial Aneurysms (SURMOUNT), and MicroVention Flow Redirection Intraluminal Device (FRED) trials. University of California, San Francisco has research contracts for evaluation of Siemens angiography equipment; Royalties: Penumbra, Comments: potential royalties from a preclinical device in oncology; Stock/Stock Options: Medina Medical, Comments: stock options earned for participation on scientific advisory board before company acquisition. J. Mocco-UNRELATED: Consultancy: Lazurus Effect, Reverse Medical, Pulsar, Edge Therapeutics, Medina. Joey English- 
UNRELATED: Consultancy: Stryker Neurovascular, Medtronic, Silk Road Medical, Comments: unrelated to the Transform Balloon or any work described in the manuscript; Expert Testimony: expert witness regarding neurointerventional procedures (unrelated to the use of the Transform Balloon Microcatheter); Payment for Development of Educational Presentations: Stryker Neurovascular, Comments: assisted in the creation of educational materials regarding neurointerventional procedures for fellows, nurses, and radiology technicians. Yuichi Murayama-RELATED: Grant: Stryker*; Consulting Fee or Honorarium: Stryker, Comments: an inventor of Matrix coil; receives royalties from Stryker; UNRELATED: Grants/Grants Pending: Siemens. * Charlie J. Prestigiacomo-UNRELATED: Board Membership: International Brain Research Foundation, Comments: board member volunteer; Consultancy: Stryker, Comments: lecturer to fellowship course once per year and participant on Scientific Advisory Board, paid as honorarium and cost of travel; Stock/Stock Options: Thermopeutix, Comments: earned from participation on Scientific Advisory Board; Travel/Accommodations/Meeting Expenses Unrelated to Activities Listed: Codman, Comments: for participation on Data Safety Monitoring Board. Demetrius Lopes_UNRELATED: Consultancy: Stryker; Grants/Grants Pending: Stryker; Payment for Lectures (including service on speakers bureaus): Stryker; Payment for Development of Educational Presentations: Stryker. Kirsten Carroll-RELATED: Other: Stryker, Comments: conducted the work on this submission as part of employment duties; UNRELATED: Stock/Stock Options: Stryker. Cameron G. McDougall-UNRELATED: Consultancy: Microvention, ev3. *Money paid to the institution.

\section{REFERENCES}

1. Molyneux A, Kerr R, Stratton I, et al. International Subarachnoid Aneurysm Trial (ISAT) of neurosurgical clipping versus endovascular coiling in 2143 patients with ruptured intracranial aneurysms: a randomised trial. Lancet 2002;360:1267-74 CrossRef Medline

2. Molyneux AJ, Kerr RS, Birks J, et al. Risk of recurrent subarachnoid haemorrhage, death, or dependence and standardised mortality ratios after clipping or coiling of an intracranial aneurysm in the International Subarachnoid Aneurysm Trial (ISAT): long-term follow-up. Lancet Neurol 2009;8:427-33 CrossRef Medline
3. McDougall CG, Spetzler RF, Zabramski JM, et al. The Barrow Ruptured Aneurysm Trial. J Neurosurg 2012;116:135-44 CrossRef Medline

4. McDougall CG, Claiborne Johnston S, Gholkar A, et al. Bioactive versus bare platinum coils in the treatment of intracranial aneurysms: the MAPS (Matrix and Platinum Science) trial. AJNR Am J Neuroradiol 2014;35:935-42 CrossRef Medline

5. Molyneux AJ, Clarke A, Sneade M, et al. Cerecyte coil trial: angiographic outcomes of a prospective randomized trial comparing endovascular coiling of cerebral aneurysms with either Cerecyte or bare platinum coils. Stroke 2012;43:2544-50 CrossRef Medline

6. White PM, Lewis SC, Gholkar A, et al. Hydrogel-coated coils versus bare platinum coils for the endovascular treatment of intracranial aneurysms (HELPS): a randomised controlled trial. Lancet 2011; 377:1655-62 CrossRef Medline

7. Naggara ON, Lecler A, Oppenheim C, et al. Endovascular treatment of intracranial unruptured aneurysms: a systematic review of the literature on safety with emphasis on subgroup analyses. Radiology 2012;263:828-35 CrossRef Medline

8. McDougall CG, Johnston SC, Gholkar A, et al. Counterpoint-target aneurysm recurrence: measuring what matters. AJNR Am J Neuroradiol 2015;36:4-6 CrossRef Medline

9. Pierot L, Fiehler J, White P. Point-TAR: a useful index to follow-up coiled intracranial aneurysms? AJNR Am J Neuroradiol 2015;36:2-4 CrossRef Medline

10. Raymond J, Guilbert F, Weill A, et al. Long-term angiographic recurrences after selective endovascular treatment of aneurysms with detachable coils. Stroke 2003;34:1398-403 CrossRef Medline

11. Hetts SW, Turk A, English JD, et al. Stent-assisted coiling versus coiling alone in unruptured intracranial aneurysms in the Matrix and Platinum Science trial: safety, efficacy, and mid-term outcomes. AJNR Am J Neuroradiol 2014;35:698-705 CrossRef Medline 